\title{
Addressing Domestic Abuse and Violence via a Non-Formal Environment Seen as a Pedagogical Tool at University
}

\author{
Ivanna I. Parfanovich \\ Department of Social Pedagogy and Social Work, Ternopil Volodymyr Hnatiuk \\ National Pedagogical University, Ternopil, Ukraine
}

Andrii Ya. Parfanovich

Department of Social Pedagogy and Social Work, Ternopil Volodymyr Hnatiuk National Pedagogical University, Ternopil, Ukraine

Vitalii G. Panok

Ukrainian Scientific-Methodological Center of Applied Psychology and Social Work, National Academy of Educational Sciences of Ukraine, Kyiv, Ukraine

\section{Larysa V. Zdanevych}

Department of Pre-School Pedagogy, Psychology and Professional Methods, Khmelnytskyi Humanitarian-Pedagogical Academy, Khmelnytskyi, Ukraine

\section{Liudmila I. Romanovska}

Department of Social work and Pedagogics, Khmelnytskyi National University, Khmelnytskyi, Ukraine

\begin{abstract}
The purpose of the study was to identify how family abuse and violence could be addressed via a non-formal educational environment seen as a pedagogical tool at university. The study utilised an exploratory case study design. Quantitative and qualitative data were drawn from observations of sampled students' performance in the programme entitled "Legal and Psychological Domains of Domestic Abuse and Violence" and through the interview. The Attitudes towards Domestic Violence Questionnaire (ADV), the quiz entitled "Dimensions and dynamics of family violence" was administered to measure the impact of the domestic abuse and violence on the students' awareness of legal and psychological consequences. IBM SPSS Statistics software was used to process the above data. MS Office Excel Software was used to consolidated and process the data drawn from the interview. The study showed that non-formal university settings have the potential to enrich pedagogic tools for addressing domestic abuse and violence. The prevention intervention had a positive impact on students' awareness of legal and psychological aspects of domestic abuse and violence, students' perceptions of committing abusive and/or violent actions by men and
\end{abstract}


women in family settings. It was validated by measurements, observations, and students' feedbacks. The experiment raised some implications like attracting experts, raising funds, finding sufficient evidence, and cases to fill the programme content. Further research is needed in developing methodology and instruments of evaluation of the effectiveness of such intervention programmes.

Keywords: university education; pedagogic tools of non-formal settings; educational intervention programme; domestic abuse and violence

\section{Introduction}

Domestic abuse and violence have been a social, legal, and psychological (psychiatric) problem for many generations (Barnett, Miller-Perrin \& Perrin, 2010; Ghafournia, 2017; Odenbring, Johansson, Lunneblad \& Hammarén, 2015). According to the annual police reports, in Ukraine, the figures for the issue-related cases are increasing by approximately 3\% a year (111 cases in 2017, 115 cases in 2018, and 121 cases in 2019) (ZIK, 2020). This suggests that current measures do not resolve the issue and additional targeted preventive interventions are required (Stanley, Ellis, Farrelly, Hollinghurst \& Downe, 2015). University student youth seems to be a reasonable target audience because they are classified as exposed current or former victims of domestic or peer abuse and violence (Odenbring et al., 2015) and their experience can be used to change their own beliefs and behaviour. Moreover, educational interventions are becoming standard pedagogic tools that are mostly aimed at the legal and psychological dimensions of the issue (Lloyd, 2018). They are widely used in both institutional and community settings and have proven to be effective to deal with young individuals' life crisis and to prepare the latter for 'violence-free relationships' in the future (Adelman, Rosenberg \& Hobart, 2016; Gabriel et al., 2018; HeavenOakland, n./d.; Owen, Antle \& Quirk, 2017).

\subsection{Literature review}

The literature review found that the issue has been a widely discussed and multifaceted legal, psychological, medical and scientific (educational dimension) problem for over the last decades (Crowther-Dowey, Gillespie \& Hopkins, 2016; Parkinson \& Rogers, 2019). The targeted domestic abuse prevention education programmes are run either at secondary schools (World Health Organization, 2019) or by public organisations (European Union, n./d.). They are aimed at cultivating a new culture of interpersonal relationships at schools and raise public awareness of domestic abuse and violence (Lloyd, 2018; Wagner, Jones, Tsaroucha \& Cumbers, 2019; McKibbin \& Humphreys, 2020). There are still debates in the literature concerning whether the domestic abuse and violence prevention education interventions should be based on a gendered approach (Stanley, Ellis \& Bell, 2011; Fenton \& Mott, 2017). As it was found, those programmes are delivered in conventional educational settings and using conventional pedagogical tools. For example, the "Safe to Learn" initiative intends to train children's life skills through the organised activities 'to shape their attitudes and norms' at schools (World Health Organization, 2019). The Master's degree course entitled "Abuse and gender violence: an interdisciplinary vision" also used 
conventional university approach to engage students to explore the issue from different perspectives ("Master's course in gender violence", 2015). The specialised training and certification programmes for the professionals working in the field of domestic violence prevention and elimination are also delivered conventionally (Stover \& Lent, 2014; Domestic Violence Resource Centre Victoria, n./d.).

However, this approach might seem to be quite tactless in some delicate situations that are better tackled in a non-determined environment in the community-like atmosphere (Goldman, Assaraf \& Shaharabani, 2013).

The study found few resources on intervention programmes to have been run in non-formal settings at university and formally evaluated which created the gap for the research.

Therefore, the purpose of the study was to identify how family abuse and violence could be addressed via a non-formal educational environment seen as a pedagogical tool at university.

The study sought to address the research questions below:

1. How did the prevention programme entitled "Legal and Psychological Domains of Domestic Abuse and Violence" impact on students' awareness of legal and psychological aspects of domestic abuse and violence?

2. How did the prevention programme entitled "Legal and Psychological Domains of Domestic Abuse and Violence" impact on students' gender-related perception of committing abusive and/or violent actions by men and women in family settings?

3. What were the involved students' perceptions of the project delivery format?

\section{Materials and methods}

The study utilised an exploratory single-case study design based on one group pre-test and post-test data and was conducted at Volodymyr Vynnychenko Central Ukrainian State Pedagogical University. Quantitative and qualitative data were drawn from observations of sampled students' performance in the randomised experiment and through interviews with them. The Attitudes towards Domestic Violence Questionnaire (ADV) designed by Fox and Gadd (2012) was used to explore changes in students' perceptions of men's and women's behaviour in situations of conflicts. The quiz entitled "Dimensions and dynamics of family violence" (AVERT Family Violence, 2010) (the legal domain of the issue) was administered to measure the impact of the programme entitled "Legal and Psychological Domains of Domestic Abuse and Violence" on the students' awareness of legal and psychological consequences of the domestic abuse and violence. The variables for the study were students' awareness of legal and psychological aspects of domestic abuse and violence, students' genderrelated perception of committing abusive and/or violent actions by men and women in family settings. 


\subsection{The programme}

The prevention programme entitled "Legal and Psychological Domains of Domestic Abuse and Violence" was designed to train the students in dealing with conflicts and to raise students' awareness of legal aspects of the issue (see the structure of the programme visualised in Fig. 1). The training was followed by Mock Talk Shows aimed at analysing real cases on the issues of domestic violence and abuse. Ten sessions were delivered once in two weeks throughout the period from September to the end of December of 2019 by expert practitioners and Mock Talk Shows were held by the research team members supported by invited practitioners who delivered the classes. They were domestic violence lawyers, domestic violence counsellors (psychologists and psychiatrists), and domestic violence social workers working in the field for more than ten years.

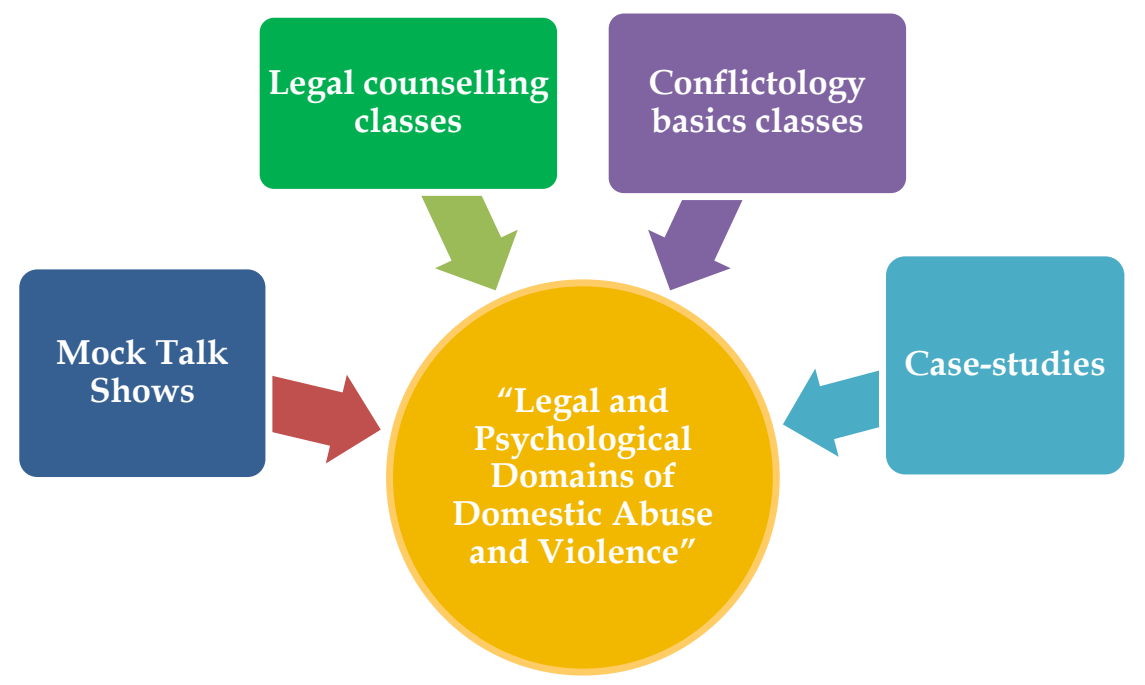

Figure 1: "Legal and Psychological Domains of Domestic Abuse and Violence" programme design

The topics for the sessions were related to forms of domestic abuse and violence, the ways to recognise them, legal punishments for committing them, effects of domestic abuse on a young person, victimisation and barriers to leaving, means and ways of dealing with conflicts, risks and causes for the commitment of family violence and abuse, etc (see the topics outlined in Table 1). The format for the Mock Talk Show was adapted from The Oprah Winfrey TV Show ${ }^{\odot}$ and the cases for the 'shows' were borrowed from the La Strada - Ukraine (n./d.). This is the NGO that actively promotes information and provides training on prevention and social assistance, and is active in the improvement of national legislation on human trafficking, sexual exploitation of children, violence, discrimination and human rights in Ukraine. 
Table 1: The outline of the topics distributed by session and hours dedicated to each topic

\begin{tabular}{|c|c|c|}
\hline $\begin{array}{l}\text {. } \\
\text {. } \\
\text { W } \\
\infty \\
\text { क } \\
\#\end{array}$ & Topic & Hours \\
\hline 1 & Forms of domestic abuse and violence. How to recognise them. & 2 \\
\hline 2 & Legal punishments for committing them. Analysing cases. & 2 \\
\hline 3 & Mock Talk Show. & 2 \\
\hline 4 & $\begin{array}{l}\text { Legal counselling basics. Building up mutual trust. Case-study. } \\
\text { Simulations. }\end{array}$ & 2 \\
\hline 5 & $\begin{array}{l}\text { Ethical issues of legal counselling on family violence and abuse. } \\
\text { Written communication. Persuasion techniques. }\end{array}$ & 2 \\
\hline 6 & Risks and causes for the commitment of family violence and abuse. & 2 \\
\hline 7 & $\begin{array}{l}\text { Effects of domestic abuse on a young person: gender issues. } \\
\text { Victimisation and barriers to leaving: gender issues. }\end{array}$ & 2 \\
\hline 8 & Mock Talk Show. & 2 \\
\hline 9 & $\begin{array}{l}\text { How to deal with abuse-based conflicts in a family. Analysing cases. } \\
\text { Quiz entitled "Strategies for Coping with Unhealthy Family } \\
\text { Behaviour" (Study.com,n./d.) }\end{array}$ & 2 \\
\hline 10 & Mock Talk Show. & 2 \\
\hline
\end{tabular}

"Safe Families Club" as a non-formal learning environment was set up to run the experiment. The project was advertised to potential participants using presentations, posters, and announcements at some lectures. The objective of this was to involve volunteers who were sensitive to the issue of domestic abuse and violence and agreed to further assist the experts who ran educational prevention interventions at three schools located in Kropyvnytskyi Town.

\subsection{Sampling}

Simple random sampling was used to hire volunteers for the study. Forty-three students in their second, third, and fourth years, majoring in Psychology, Law, and Journalism of Volodymyr Vynnychenko Central Ukrainian State Pedagogical University were encouraged to apply for participation in the training programme. The primary rationale for selecting those majors was the fact that the topic of domestic abuse and violence was related to the students' specialism. They were supposed to write a motivation letter which was used to shortlist 30 students for the interview. It was conducted by a panel of two psychology experts in the field of domestic violence and abuse. It included the questions as follows: 1) What do you see as triggers of violence and abuse in families? 2) If you were your father, how would you react to some misbehaviours of yours in the classroom? 3) Describe the worst argument you had with someone from your family and how you coped with it, etc. The selection criteria were non-violent thinking, nonproneness to aggressive dominance, or gender humiliation, being a nonvulnerable person. As the study utilised one group design, twenty-one students (13 females aged between 19 and 22 and 8 males aged between 19 and 21) were sampled for the intervention. They were considered mutually homogeneous as they had gone through the above selection procedure. At this stage, the pretreatment measurements, including the Attitudes towards Domestic Violence 
Questionnaire (ADV) and a quiz entitled "Family Violence \& Abuse" (ClickLaw WikiBooks, n./d.) were administered.

\subsection{Major research-related ethical issues}

Before the experiment, written informed consent was obtained from the sampled students to address the confidentiality of their personal information (Cacciattolo, 2015; Akaranga \& Makau, 2016). The "primum non nocere" ["first, do no harm"] principle was followed at every stage of the study to avoid or minimise any deliberate or potential harm. The sampled students were treated as nonvulnerable (Drew, Hardman \& Hosp, 2008) for a reason being that they lived on campus but not with their families.

\subsection{Instruments}

The study used such quantitative tools as observation reports, evaluation sheets, student attendance records, the Questionnaire on Attitudes towards Domestic Violence (ADV) (Fox \& Gadd, 2012) and quizzes entitled "Family Violence \& Abuse" (ClickLaw WikiBooks, n./d.) and "Dimensions and dynamics of family violence" (AVERT Family Violence, 2010). To ensure the reliability of the observation reports, behavioural code description was developed and three assessors were hired to take records. Data were simultaneously collected by all assessors on each separate session. Kappa Online Calculator (Statistics Solution, n./d.) was used to assesses the inter-rater reliability of three raters drawn from the observation reports, evaluation sheets, student attendance records. The kappa coefficient was 0.74 which was substantial and proved that the measurements were reliable.

The questionnaire on attitudes towards domestic violence proved to be an effective tool that can be used to assess the effectiveness of domestic abuse prevention programmes (Fox, Gadd \& Sim, 2015). At the pre-test stage, it aimed at exploring students' experience of domestic violence and abuse as victims, perpetrators and as witnesses.

IBM SPSS Statistics software was used to process the above data.

Additionally, the questionnaire for interviewing sampled students was used to obtain qualitative data. It comprised five open-ended questions which were as follows:

1) How did the programme influence your beliefs?

2) What were your gains from this programme?

3) Did you appreciate the non-formal format of the pedagogical engagement?

4) What were the problems you faced or challenged as a participant and assistant in the project?

5) What do you suggest improving so that the programme addressed those problems?

MS Office Excel Software was used to consolidated and process the data drawn from the interview. 


\section{Results}

The prevention programme entitled "Legal and Psychological Domains of Domestic Abuse and Violence" and "Safe Families Club" have appeared to be the most significant result of this research which brought a number of benefits to the sampled students.

The repeated measurements of the students' awareness of legal and psychological aspects of domestic abuse and violence (see Table 2), students' gender-related perception of committing abusive and/or violent actions by men and women in family settings proved the relationship between participation of the students in the prevention programme and the changes to have occurred in the variables.

Table 2: Relation between the participation of the students in the programme and their awareness of family abuse expressed as proportions of correct/incorrect answers in quizzes before and after the intervention, in $\%$

\begin{tabular}{|c|c|c|c|c|c|}
\hline \multirow{2}{*}{$n$} & \multicolumn{2}{|c|}{ Before Intervention } & \multicolumn{2}{|c|}{ After Intervention } & \multirow{2}{*}{\begin{tabular}{c} 
Quiz \\
\cline { 2 - 5 }
\end{tabular}} \\
\cline { 2 - 5 } & "Family Violence \& Abuse" & \multicolumn{2}{|c|}{$\begin{array}{c}\text { "Dimensions and dynamics of } \\
\text { family violence" Quiz }\end{array}$} & \\
\hline \multirow{2}{*}{$n=21$} & IA & CA & IA & CA & \multirow{2}{*}{19} \\
\cline { 2 - 5 } & $53 \%$ & $47 \%$ & $33 \%$ & $67 \%$ & \\
\hline
\end{tabular}

Note: IA - incorrect answers; CA - correct answers.

As can be seen, the proportion of the correct answers increased by $20 \%$ which indicated the programme boosted students' knowledge related to the issue.

The results that were obtained at pre-test and post-test stages through the questionnaire on attitudes towards domestic violence and compared at the posttest stage showed a decrease in victimisation (before the intervention: $F_{1.0891}=$ $4.02 ; p=0.41 ; \mathrm{p}<.001 \mathrm{VS}$ after the intervention $\left.F_{0.9214}=3.79 ; p=0.37 ; p<.001\right)$ and perpetration (before the intervention: $F_{1.1062}=13.31 ; p=0.04 ; p<.001$ VS after the intervention: $F_{0.9932}=11.79 ; p=0.33 ; p<.001$ ) characteristics in the sampled students. It suggested that the educational environment raised students' self-confidence in dealing with violent actions towards them.

The change in perceptions of committing abusive and/or violent actions by men and women in family settings also took place after the intervention (see Table 3).

Table 3: Change in approval of abusive and/or violent actions by men and women in

the family to have taken place due to the intervention based on the ADV questionnaire (12-item version), item-total correlations (ITC), before and after the intervention

\begin{tabular}{|c|c|c|c|c|c|c|}
\hline \multirow[b]{2}{*}{ 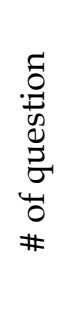 } & \multicolumn{3}{|c|}{ Before Intervention } & \multicolumn{3}{|c|}{ After Intervention } \\
\hline & 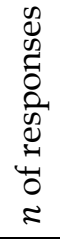 & $\begin{array}{c}\text { approval, } \\
\%\end{array}$ & ITC & 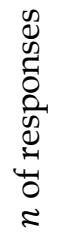 & $\begin{array}{c}\text { approval, } \\
\%\end{array}$ & ITC \\
\hline 1 & 20 & 83 & .637 & 17 & 31 & .560 \\
\hline 2 & 16 & 39 & .641 & 19 & 21 & .591 \\
\hline 3 & 21 & 47 & .608 & 20 & 12 & .598 \\
\hline 4 & 13 & 56 & .557 & 21 & 18 & .512 \\
\hline
\end{tabular}




\begin{tabular}{|c|c|c|c|c|c|c|}
\hline 5 & 20 & 35 & .656 & 14 & 11 & .523 \\
\hline 6 & 18 & 51 & .643 & 18 & 17 & .511 \\
\hline 7 & 19 & 63 & .669 & 17 & 22 & .533 \\
\hline 8 & 15 & 78 & .778 & 15 & 32 & .611 \\
\hline 9 & 21 & 74 & .634 & 20 & 29 & .602 \\
\hline 10 & 21 & 66 & .671 & 20 & 24 & .594 \\
\hline 11 & 17 & 41 & .665 & 18 & 18 & .601 \\
\hline 12 & 19 & 52 & .751 & 21 & 22 & .627 \\
\hline
\end{tabular}

Note: The questions are laid out in the order they appear on the questionnaire. ITC - Item-total correlation

The figures in Table 3 illustrated a marked decrease in the approval of abusive and violent deeds of partners in family settings.

The observation reports of the research team members and evaluation sheets also proved that the students suggested two primary justifiable reasons for abuse or violence from both sides (from men or women): who attacked or hurt first and who cheated first. Moreover, females are easier than males to forgive their partners either abuse or violence or cheating in their family relationships. Seven out of eight sampled male students tended to justify a violent or abusive response in the situations in which women were drunk or drugged or they humiliated/offended males in some way (especially publicly), they were angry and shouted at males.

The figures in Table 4 reveal the shift in sampled students' knowledge of core legal and psychological aspects of domestic abuse and violence and their skills and abilities to deal with them before and after the intervention.

Table 4: Students' pre-test and post-test measurement results in the knowledge of core aspects of domestic abuse and violence and their skills and abilities to deal with them, expressed as mean values obtained from measurements before and after the intervention

\begin{tabular}{|c|c|c|c|c|c|c|c|c|c|c|}
\hline \multirow{2}{*}{$\mathrm{N}$} & \multicolumn{2}{|c|}{ KCLA } & \multicolumn{2}{|c|}{ KCPA } & \multicolumn{2}{|c|}{ SA } & $\begin{array}{c}\text { Cronbac } \\
\text { h's alpha }\end{array}$ & SD & $\mathrm{t}$ & $\begin{array}{c}\mathrm{p} \\
\text { value }\end{array}$ \\
\cline { 2 - 10 } & $\mathrm{B}$ & $\mathrm{A}$ & $\mathrm{B}$ & $\mathrm{A}$ & $\mathrm{B}$ & $\mathrm{A}$ & & & & \\
$\mathrm{n}=21$ & 57.87 & 74.11 & 48.58 & 69.13 & 43.21 & 69.11 & $\begin{array}{c}0.783 \\
(>0.7)\end{array}$ & 721 & 0.73 & 0.38 \\
\hline
\end{tabular}

Note: B - Before; A - After; KCLA - knowledge of core legal aspects; KCPA - knowledge of core psychological aspects; $S A$ - skills and abilities to deal with the issues.

The above suggests that the sampled students experienced a statistically significant change (of approximately $16 \%$ ) in awareness of legal and psychological aspects of domestic violence and abuse and improved their skills of dealing with them.

\subsection{Results of Semi-structured Interview (EG students, $n=21, d f=2$ )}

Question 1. How did the programme influence your beliefs? Seventeen respondents reported a radical change in their attitudes to some domestic abusive and violent behaviours. Four participants were still convinced that women's behaviour was the key trigger of a conflict in a family.

Question 2. What were your gains from this programme? Twelve people reported that they learned how to control their behaviour when the conflict situation 
emerged. Seven people confessed that training sessions developed their selfconfidence when dealing with people causing trouble. One student reported progress in communication with 'difficult' people. One participant found the programme useful for their relationships.

Question 3. Did you appreciate the non-formal format of the pedagogical engagement? Eleven people found the format to be optimal for this very issue. Eight people stated it was OK for them. Two participants stated that the format did not fit their learning style.

Question 4. What were the problems you faced or challenged as a participant and assistant in the project? Two respondents reported they were overloaded with information. Two participants stated that the format did not fit their learning style.

Question 5. What do you suggest improving so that the programme addressed those problems? Nineteen students suggested training them in NLP and debating before the intervention.

The students' responses to the interview questions imply that students were generally positive about the format of the project and appreciated the outcomes.

\section{Discussion}

This study has been the first attempt in Ukraine to evaluate the effectiveness of using prevention programme entitled "Legal and Psychological Domains of Domestic Abuse and Violence" delivered through a non-formal environment at university and how this programme influenced students' gender-related perceptions of committing abusive and/or violent actions by men and women in family settings. Additionally, it aimed at exploring students' perceptions of the project delivery format. It was found that the students' awareness of legal and psychological aspects of domestic abuse and violence increased by about $20 \%$, the approval of abusive and violent deeds of partners in family settings decrease by approximately substantially, the students' skills of dealing with domestic violence and abuse and improved by about $16 \%$. The results that were obtained at pre-test and post-test stages through the questionnaire on attitudes towards domestic violence and compared at the post-test stage showed a decrease in victimisation and perpetration characteristics in the sampled students, which indicated that the educational environment raised students' self-confidence in dealing with violent actions towards them.

The above results addressed the questions of this study and complied with literature highlighting best prevention practices in coping with domestic abuse and violence (European Institute for Gender Equality, 2015; Katz \& McGuire, 2018; Pisani Altafim \& Martins Linhares, 2016). The findings, which were in line with previous studies (Institute of Medicine and National Research Council, 1998), from the study proved that the quality of educational prevention intervention improved when conducted jointly by a practitioner from the issue field and an educator. This is due to the fact (Grimmer, 2016) that young people are sensitive to issues like trust, betrayal, love, friendship, and respect the experts' opinions, trust them more than their relatives or friends. 
The study goes in line with Fox, Hale \& Gadd (2014) stating that the concerns related with domestic abuse and violence in young people should be anticipated in the student-tailored education programmes in the class and out-of-class activities at school and university. This was also found in the study that nonformal university settings and the age of the students were favourable prerequisites for addressing domestic abuse and violence. This study is also consistent with the findings of Roy, Lindsay \& Dallaire, (2013) whose research demonstrated the importance of establishing cooperation with the specialist facilitators from external agencies to support teachers in the educational interventions of this kind.

The experiment provides a new insight into the prevention educational project management that can be delivered non-formally and with the involvement of the expert facilitators from the external institutions.

The reason for this is that high rates of abuse and violence, to have been performed to and by young people, are found (see the Introduction section).

The study contributed to the pedagogic domain of dealing with the issue of family abuse and violence by exploring non-formal university settings.

\subsection{Limitations of the study}

The results of the study might be challenged because of the number of sampled students, the duration of the experiment, and instrumentation used to obtain statistical data. Moreover, the study did not assess the actual behaviour of the respondents but only their attitudes towards domestic violence and abuse. The results of the research only rely on one group of sampled students. And one can argue that there is no alternative explanation of the results.

\section{Conclusion}

The study showed that the non-formal university settings have the potential to enrich pedagogic tools for addressing domestic abuse and violence. The prevention intervention organised in the way presented had a positive impact on students' awareness of legal and psychological aspects of domestic abuse and violence, students' perceptions of committing abusive and/or violent actions by men and women in family settings. It was validated by measurements, observations, and students' feedbacks. The pre-test and post-test results proved that the project to have been delivered through the non-formal educational environment had a positive outcome in terms of a reduction of victimisation and perpetration characteristics in involved students and an increase in students' selfconfidence in tackling violent actions towards them in both family and educational environment.

The results obtained directly and indirectly from the research implied that the issue is still gender-stereotyped and young people need extensive training in establishing and maintaining relationships with representatives of the opposite gender. The programmes of such kind should be incorporated into the university curriculum as an optional or elective course. Furthermore, both teachers' and involved experts' knowledge of students' experiences and learning preferences are a prerequisite for success of this intervention. 
The experiment also raised some implications like attracting experts, raising funds, finding sufficient evidence, and cases to fill the programme content. Further research is needed in developing methodology and tools for evaluation of the effectiveness of such intervention programmes.

\section{References}

Adelman, M., Rosenberg, K. E., \& Hobart, M. (2016). Simulations and social empathy: domestic violence education in the new millennium. Violence Against Women, 22(12), 1451-1462. https:// doi.org/10.1177/1077801215625850

Akaranga, S. I, \& Makau, B. K. (2016). Ethical Considerations and their Applications to Research: A Case of the University of Nairobi. Journal of Educational Policy and Entrepreneurial, 3(12), 1-9.

AVERT Family Violence. (2010). Quiz on dimensions and dynamics of family violence. Australian Attorney-General's Department. Retrieved from https://www.avertfamilyviolence.com.au/wp-

content/uploads/sites/4/2013/06/Dimensions_and_Dynamics_of_Family_Viol ence_Quiz_With_Answers_for_web_2014.pdf

Barnett, O. W., Miller-Perrin, C. L., \& Perrin, R. D. (2010). Family violence across the lifespan: An introduction ( $\left.3^{\text {rd }} \mathrm{ed}\right)$. Thousand Oaks, CA: SAGE Publications.

Cacciattolo, M. (2015). Ethical Considerations in Research. In: M. Vicars, S. Steinberg, T. McKenna, \& M. Cacciattolo (Eds.), The Praxis of English Language Teaching and Learning (PELT) (pp. 61-79). Rotterdam, Netherland: SensePublishers. https://doi.org/10.1007/978-94-6300-112-0_4

ClickLaw WikiBooks. (2020). Family Violence \& Abuse Quiz. Retrieved from https://wiki.clicklaw.bc.ca/index.php?title=Family_Violence_\%26_Abuse_Quiz

Crowther-Dowey, C., Gillespie, T., \& Hopkins, K. (2016). Building healthy relationships for young people and the prevention of domestic abuse. In: S. Hilder, \& V. Bettinson (Eds.), Domestic Violence (pp 155-179). London, UK: Palgrave Macmillan. https://doi.org/10.1057/978-1-137-52452-2_8

Domestic Violence Resource Centre Victoria. (2020). Our Courses. Retrieved from https://training.dvrcv.org.au/our-courses/

Drew, C. J., Hardman, M. L., \& Hosp, J. L. (2008). Ethical issues in conducting research. In: C. J. Drew, M. L. Hardman, \& J. L. Hosp (Eds.), Designing and conducting research in education (pp. 55-80). Thousand Oaks, CA: SAGE Publications, Inc. https://doi.org/10.4135/9781483385648

European Institute for Gender Equality. (2015). Master's course in gender violence improves professional practice. Retrieved from https://eige.europa.eu/gender-basedviolence/good-practices/spain/masters-course-gender-violence-improvesprofessional-practice

European Institute for Gender Equality. (2015). Preventing domestic violence: Good practices. Retrieved from https://eige.europa.eu/sites/default/files/documents/MH0114678ENN_WEB. PDF

European Union. (2020). Domestic Abuse Intervention Centres/Violence Protection Centres. Retrieved from https://ejustice.europa.eu/content_rights_of_victims_of_crime_in_criminal_proceedings171-AT-en.do?clang=en\&idSubpage $=4 \&$ member $=1 \#$ n03

Fenton, R. A., \& Mott, H. L. (2017). The bystander approach to violence prevention: Considerations for implementation in Europe. Psychology of Violence, 7(3), 450458. https://doi.org/10.1037/vio0000104 
Fox, C. L., Gadd, D., \& Sim, J. (2015). Development of the Attitudes to Domestic Violence Questionnaire for Children and Adolescents. Journal of Interpersonal Violence, 30(14),_2506-2525. https://doi.org/10.1177\%2F0886260514553115

Fox, C. L., Hale, R., \& Gadd, D. (2014). Domestic abuse prevention education: listening to the views of young people. Sex Education, 14:1, 28-41. https://doi.org/10.1080/14681811.2013.816949

Fox, C., \& Gadd, D. (2012). Attitudes towards Domestic Violence Questionnaire (ADV). Retrieved from https://www.keele.ac.uk/readapt/sites/default/files/documents/ADV\%20Qu estionnaire.pdf

Gabriel, L., Tizro, Z., James, H., Cronin-Davis, J., Beetham, T., Corbally, A., Lopez-Moreno, E., \& Hill, S. (2018). "Give me some space": exploring youth to parent aggression and violence. Journal of Family Violence, 35(3), 161-169. https://doi.org/10.1007/s10896-017-9928-1

Ghafournia, N. (2017). Muslim women and domestic violence: Developing a framework for social work practice. Journal of Religion \& Spirituality in Social Work: Social Thought, 36(1-2), 146-163. https://doi.org/10.1080/15426432.2017.1313150

Goldman, D., Assaraf, O., \& Shaharabani, D. (2013). Influence of a Non-formal Environmental Education Programme on Junior High-School Students' Environmental Literacy. International Journal of Science Education, 35, 515-545. https://doi.org/10.1080/09500693.2012.749545

Grimmer, J. (2016). Experts vs. Friends: The Definitive Guide to Who Influences Us and Why. Retrieved from https://medium.com/bestcompany/experts-vs-friends-thedefinitive-guide-to-who-influences-us-and-why-6a0aa609c8c0

Heaven-Oakland. (2020). Domestic violence and sexual assault prevention education programs. Retrieved from https://www.haven-oakland.org/educationprevention/programs

Institute of Medicine and National Research Council. (1998). Violence in Families: Assessing Prevention and Treatment Programs. Washington, DC: The National Academies Press. https://doi.org/10.17226/5285.

Katz, S. M., \& McGuire, L. J. (2018). Intimate partner violence in higher education. Intimate partner violence in higher education: integrated approaches for reducing domestic violence and sexual assault on campus. In: H. Shapiro (Ed.), The Wiley Handbook on Violence in Education: Forms, Factors, and Preventions (pp. 417-431). Medford, MA: John Wiley \& Sons, Inc.

La Strada - Ukraine. (2020). Stories of survivors. Retrieved from http://www.lastrada.org.ua/ucp_mod_information_showcategory_58.html

Lloyd, M. (2018). Domestic Violence and Education: Examining the Impact of Domestic Violence on Young Children, Children, and Young People and the Potential Role of Schools. Frontiers in Psychology, 9, 2094. https://doi.org/10.3389/fpsyg.2018.02094

McKibbin, G., \& Humphreys, C. (2020). Future directions in child sexual abuse prevention: An Australian perspective. Child Abuse \& Neglect, 104422. In Press. https://doi.org/10.1016/j.chiabu.2020.104422

Odenbring, Y., Johansson, T., Lunneblad, J., \& Hammarén, N. (2015). Youth victimisation, school, and family support: schools' strategies to handle abused children. Education Inquiry, 6(2), 26417. https:/ / doi.org/10.3402/edui.v6.26417

Owen, J., Antle, B., \& Quirk, K. (2017). Individual relationship education program as a prevention method for intimate partner violence. Journal of Family Social Work, 20(5), 457-469. https://doi.org/10.1080/10522158.2017.1300112 
Parkinson, K., \& Rogers, M. (2019). Addressing domestic abuse through FGCs. In: D. Edwards, \& K. Parkinson (Eds.), Family Group Conferences in Social Work: Involving Families in Social Care Decision Making. https://doi.org/10.1332/policypress/9781447335801.003.0008

Pisani Altafim, E. R., \& Martins Linhares, M. B. (2016). Universal violence and child maltreatment prevention programs for parents: A systematic review. Psychosocial Intervention, 25(1), 27-38. https:/ / doi.org/10.1016/j.psi.2015.10.003

Roy, V., Lindsay, J., \& Dallaire, L.-F. (2013). Mixed-Gender Co-Facilitation in Therapeutic Groups for Men Who Have Perpetrated Intimate Partner Violence: Group Members' Perspectives. The Journal for Specialists in Group Work, 38(1), 3-29. https:// doi.org/10.1080/01933922.2012.732981

Stanley, N., Ellis, J., \& Bell, J. (2011). “Delivering Preventative Programmes in Schools: Identifying Gender Issues." In Children Behaving Badly? Peer Violence Between Children and Young People, edited by Christine Barter and David Berridge, 217230. Chichester: Wiley-Blackwell.

Stanley, N., Ellis, J., Farrelly, N., Hollinghurst, S., \& Downe, S. (2015). Preventing domestic abuse for children and young people: A review of school-based interventions. Children and Youth Services Review, 59, 120-131. https://doi.org/10.1016/j.childyouth.2015.10.018

Statistics Solution. (2020). Kappa Calculator. Retrieved from https://www.statisticssolutions.com/kappa-calculator/

Stover, C. S., \& Lent, K. (2014). Training and certification for domestic violence service providers: The need for a national standard curriculum and training approach. Psychology of Violence, 4(2), 117-127. https://doi.org/10.1037/a0036022

Study.com. (2020). Quiz: "Strategies for Coping with Unhealthy Family Behavior". Retrieved from https://study.com/academy/practice/quiz-worksheet-dealing-withfamily-conflict.html

Wagner, J., Jones, S., Tsaroucha, A., \& Cumbers, H. (2019). Intergenerational transmission of domestic violence: practitioners' perceptions and experiences of working with adult victims and perpetrators in the UK. Child Abuse Review, 28(1), 39-51. https://doi.org/10.1002/car.2541

World Health Organization. (2019). School-based violence prevention: a practical handbook. Retrieved from https://www.unicef.org/media/58081/file/UNICEF-WHOUNESCO-handbook-school-based-violence.pdf

ZIK. (2020). Imprisonment for Domestic Violence Required - How Domestic Violence and Abuse are dealt with in Ukraine and the World. Retrieved from https://zik.ua/news/2019/11/22/za_domashnie_nasylstvo_za_hraty_yak_v_ ukraini_ta_sviti_boriatsia_zi_znushchanniam_u_rodyni_946146 